\title{
NOTE UPON THE HISTORY OF THE RULES OF CONVERGENCE IN THE EIGHTEENTH CEN- TURY.*
}

BY PROF. G. ENESTRÖM.

IN the introduction to his interesting article "Evolution of Criteria of Convergence" (BULLETIN OF THE NEW YORK Mathenatical Society, vol. 2, 1892, pp. 1-10), Professor Cajori mentioned several authors previous to the present century who had recognized the necessity of verifying the convergence of a series before making use of it in mathematical investigations. In this brief note $I$ beg to call attention to two other mathematicians, Maclaurin and Stirling, who had considered rules of convergence; the first of these deserves, in my opinion, a signal place in the history of these rules.

In fact, the fundamental theorem of convergence attributed (l. c., p. 3) by. Professor Cajori to Cauchy was established previously by Maclaurin in article 350 of his "Treatise on Fluxions" (Edinburgh, 1742). It is true that Maclaurin enunciated the rule in a geometrical form, but it is very easy to translate it into algebraic language. The fact that this rule is due to Maclaurin was pointed out, I believe, by Montucla, but it does not seem to have been sufficiently appreciated until quite recently. I called attention to it in the Bibliotheca Mathematica, 1886, p. 48 , and it was mentioned later by R. Reiff in his "Geschichte der unendlichen Reihen" (Tübingen, 1889, p. 120), as well as by W. W. R. Ball in the second edition of his "Short Account of the History of Mathematics" (London, 1893, p. 394).

As regards Stirling, he demonstrated in his "Methodus Differentialis" (London, 1r30) the following theorem: Let

and

$$
W=w_{0} \cdot w_{1} \cdot w_{2} \cdot w_{3} \ldots
$$

$$
w_{z}=\frac{1}{m} \frac{z^{\theta}+a z^{\theta+1}+b z^{\theta+2}+\ldots}{z^{\theta}+c z^{0+1}+d z^{\theta+2}+\ldots}
$$

then

$$
\begin{aligned}
& W=0, \text { if } m>1, \text { or if } m=1 \text { and } a<c ; \\
& W=\text { a finite quantity }<0, \text { if } m=1, a=c ; \\
& W=\infty, \text { if } m<1, \text { or if } m=1 \text { and } a>c .
\end{aligned}
$$

* Translated by the Editors. 
It is easily seen that this theorem plays the same rôle in the theory of infinite products that is taken by Gauss's rule of convergence, to which Professor Cajori refers on the second page of his note, in the theory of infinite series. Stirling attempted to make use of this theorem in order to establish the convergence of certain infinite series, but his efforts in this direction met with little success. More complete information in regard to Stirling's theorem and its applications to series are contained in my note "Ett konvergens kriterium från bôrjan of 1\%00-talet" (A rule of convergence of the beginning of the eighteenth century) inserted in the Bulletin (Öfversigt) of the Academy of Sciences of Stockholm, 18r9, No. 9, pp. $r 1-84$.

Sтоскнотм, March 31, 1894.

\section{MEYER'S REPORT ON THE 'THEORY OF INVARIAN'TS.}

Bericht über clen gegenwärtigen Stand der Invariantentheorie von Dr. Franz Meyer, Professor a. d. kgl. Bergakademie, Clausthal. Contained in Vol. I. of the Jahresbericht der deutschen Mathematiker-Vereinigung, pp. 79-292. Berlin, Reimer, 1892. 8vo.

BoTH as regards its problems and as regards its methods, the theory of invariants presents a more heterogeneous mass of materials for the summarizer of its history to deal with than do most of the mathematical disciplines which have undergone so rapid a development during the second half of our century. Dr. Franz Meyer undertook, therefore, a less attractive task in preparing his " Bericht über den gegenwärtigen Stand der Invariantentheorie " than will fall to the lot of those who will assume similar labors for the German mathematical society in other fields. With infinite patience and comprehensive knowledge, Dr. Meyer has given us, in a volume of 200 pages, a condensed statement, not only of all the methods, but of a large part of the results, of research in the field of invariants, from its beginning in the discoveries of Boole, in 1841, to the very date of the preface to the present work, August, 1892. The period 1841-6r is, indeed, passed over more summarily than the last quarter-century, the memorable work done by Cayley, Sylvester, Hermite, Brioschi, and others in the earlier period being surveyed in a brief " Rückblick," though to some extent also discussed in the body of the report.

It is quite impossible to summarize in a few pages what is already in 200 pages a condensed summary; we shall therefore content ourselves with pointing out a few features of the Re- 